\title{
Rimonabant Precipitates Anxiety in Rats Withdrawn from Palatable Food: Role of the Central Amygdala
}

\begin{abstract}
Angelo Blasio', Attilio lemolo', Valentina Sabino', Stefania Petrosino ${ }^{2}$, Luca Steardo ${ }^{3}$, Kenner C Rice ${ }^{4}$, Pierangelo Orlando ${ }^{5}$, Fabio Arturo lannotti ${ }^{2}$, Vincenzo Di Marzo ${ }^{2}$, Eric P Zorrilla*,6,7 and Pietro Cottone*, ${ }^{*, 7}$

'Laboratory of Addictive Disorders, Department of Pharmacology and Psychiatry, Boston University School of Medicine, Boston, MA, USA; ${ }^{2}$ Endocannabinoid Research Group, Institute of Biomolecular Chemistry, National Research Council, Pozzuoli, Italy; ${ }^{3}$ Department of Physiology and Pharmacology, University of Rome "Sapienza", Rome, Italy; ${ }^{4}$ Chemical Biology Research Branch, National Institute on Drug Abuse and National Institute on Alcohol and Alcoholism, Rockville, MD, USA; ${ }^{5}$ Endocannabinoid Research Group, Institute of Protein Biochemistry, National Research Council, Naples, Italy; ${ }^{6}$ Committee on the Neurobiology of Addictive Disorders, Scripps Research Institute, La Jolla, CA, USA
\end{abstract}

\begin{abstract}
The anti-obesity medication rimonabant, an antagonist of cannabinoid type-I $\left(C B_{1}\right)$ receptor, was withdrawn from the market because of adverse psychiatric side effects, including a negative affective state. We investigated whether rimonabant precipitates a negative emotional state in rats withdrawn from palatable food cycling. The effects of systemic administration of rimonabant on anxiety-like behavior, food intake, body weight, and adrenocortical activation were assessed in female rats during withdrawal from chronic palatable diet cycling. The levels of the endocannabinoids, anandamide and 2-arachidonoylglycerol (2-AG), and the CB, receptor mRNA and the protein in the central nucleus of the amygdala (CeA) were also investigated. Finally, the effects of microinfusion of rimonabant in the CeA on anxiety-like behavior, and food intake were assessed. Systemic administration of rimonabant precipitated anxiety-like behavior and anorexia of the regular chow diet in rats withdrawn from palatable diet cycling, independently from the degree of adrenocortical activation. These behavioral observations were accompanied by increased 2-AG, CB, receptor mRNA, and protein levels selectively in the CeA. Finally, rimonabant, microinfused directly into the CeA, precipitated anxiety-like behavior and anorexia. Our data show that (i) the 2-AG-CB, receptor system within the $\mathrm{CeA}$ is recruited during abstinence from palatable diet cycling as a compensatory mechanism to dampen anxiety, and (ii) rimonabant precipitates a negative emotional state by blocking the beneficial heightened 2-AG-CB, receptor signaling in this brain area. These findings help elucidate the link between compulsive eating and anxiety, and it will be valuable to develop better pharmacological treatments for eating disorders and obesity.

Neuropsychopharmacology (2013) 38, 2498-2507; doi:I0.1038/npp.2013.153; published online 17 July 2013
\end{abstract}

Keywords: obesity; eating disorders; compulsive eating; withdrawal; SRI4I7I6A; endocannabinoids

\section{INTRODUCTION}

The endocannabinoid (eCB) system is densely distributed in key brain regions that subserve feeding, motivation, and stress. Accordingly, a growing literature highlights its pivotal role in the modulation of food intake, drug abuse, and anxiety (Di Marzo et al, 2011; Gaetani et al, 2008; Kirkham, 2009; Pacher et al, 2006; Patel and Hillard, 2008; Sidhpura and Parsons, 2011; Supplementary ref 1-2). Rimonabant, an antagonist of the type-1 cannabinoid $\left(\mathrm{CB}_{1}\right)$ receptor, was approved in 2006 in several countries

\footnotetext{
* Correspondence: Dr P Cottone, Laboratory of Addictive Disorders, Department of Pharmacology and Psychiatry, Boston University School of Medicine, 72 E Concord Street, R-618, Boston, MA 021 I8, USA. Tel: + | 617638 5662, Fax: + 617638 5668, E-mail: cottone@bu.edu or Dr EP Zorrilla, Committee on the Neurobiology of Addictive Disorders, SP30-2400, Scripps Research Institute, $10550 \mathrm{~N}$ Torrey Pines Road, La Jolla, CA 92037, USA, Tel: + I 858784 7416, Fax: + I 858784 7405, E-mail: ezorrill@scripps.edu

${ }^{7}$ These authors equally contributed to this work.

Received 29 December 2012; revised I 5 June 2013; accepted 17 June 2013; accepted article preview online 24 June 2013
}

for the treatment of obesity; however, it was withdrawn from the market 2 years thereafter because of adverse psychiatric side effects, which included a negative affective state (Moreira et al, 2009; Supplementary ref 3-6). Here, we provide evidence that rimonabant may precipitate a withdrawal-like state in patients with obesity or eating disorders, analogous to the withdrawal-like state that receptor antagonists of a drug of abuse can precipitate in drug-dependent subjects. Eating disorders and obesity, similarly to drug addiction, can be conceptualized as chronic relapsing conditions with alternating periods of abstinence (eg, dieting) and relapse (compulsive overeating of palatable foods; Corwin and Grigson, 2009; Cottone et al, 2009a; Epstein and Shaham, 2010; Johnson and Kenny, 2010; Parylak et al, 2011). Chronic, intermittent drug use can result in affective dependence over repeated cycles of abuse and abstinence, culminating with the emergence of a negative emotional state (eg, dysphoria, anxiety, irritability) when drug use ceases or is prevented ('withdrawal'; Koob and Volkow, 2010). For many drugs of abuse, emotional or physical signs of withdrawal also can be triggered by pharmacologically blocking the effects of the reinforcing 
drug, eliciting a 'precipitated withdrawal' syndrome (eg, naltrexone/naloxone-opiate withdrawal; flumazenil-benzodiazepine withdrawal; mecamylamine-nicotine withdrawal; Liu and Schulteis, 2004; Lukas and Griffiths, 1982; Malin et al, 1994; Supplementary ref 7-8). Accordingly, rimonabant administration can precipitate withdrawal symptoms in both cannabinoid and opiate dependence (Navarro et al, 2001; Rodriguez de Fonseca et al, 1997; Valverde et al, 2000). Interestingly, withdrawal-like symptoms can be triggered by pharmacological blockade even when subjects are abstaining from the substance of abuse, putatively reflecting abuse-induced neuroadaptation (Avena et al, 2008; Goldberg and Schuster, 1969; Paterson and Markou, 2004; Rosenberg and Chiu, 1982; Supplementary ref 9-21). The present study tested the hypothesis that rimonabant treatment precipitates a negative emotional state in rats withdrawn from a chronic, intermittent access to a highly palatable diet.

\section{MATERIALS AND METHODS}

Please see Supplementary Material for additional details.

\section{Subjects}

Female Wistar rats $(n=229)$, weighing $126-150 \mathrm{~g}$ and 41 - to 47-day old upon arrival (Charles River, Wilmington, MA), were housed in wire-topped, plastic cages $(27 \times 48 \times 20 \mathrm{~cm})$ in a $12: 12 \mathrm{~h}$ reverse light cycle (lights off at 1000 hours), in a humidity- $(60 \%)$ and temperature-controlled $\left(22^{\circ} \mathrm{C}\right)$ vivarium. Rats had access to chow (Harlan Teklad LM-485 Diet 7012 (58\% (kcal) carbohydrate, 17\% fat, 25\% protein $310 \mathrm{cal} / 100 \mathrm{~g})$; Harlan, Indianapolis, IN) and water ad libitum at all times, unless otherwise stated. Procedures adhered to the National Institutes of Health Guide for the Care and Use of Laboratory Animals (NIH publication number 85-23, revised 1996) and the Principles of

a $\quad$ Week 1 Week 2 Week 3 Week 4 Week 5 Week 6 Week 7 Week 8

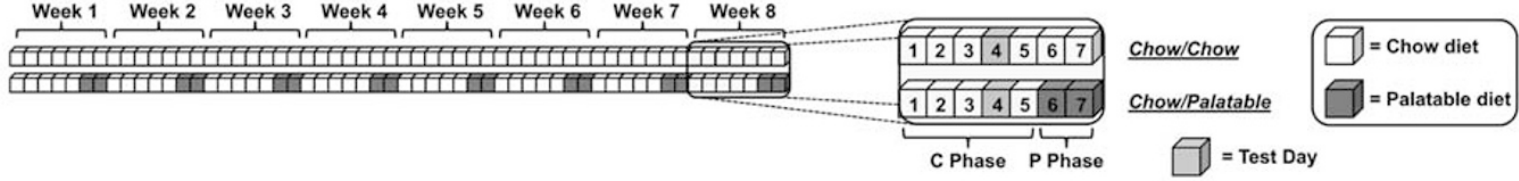

b
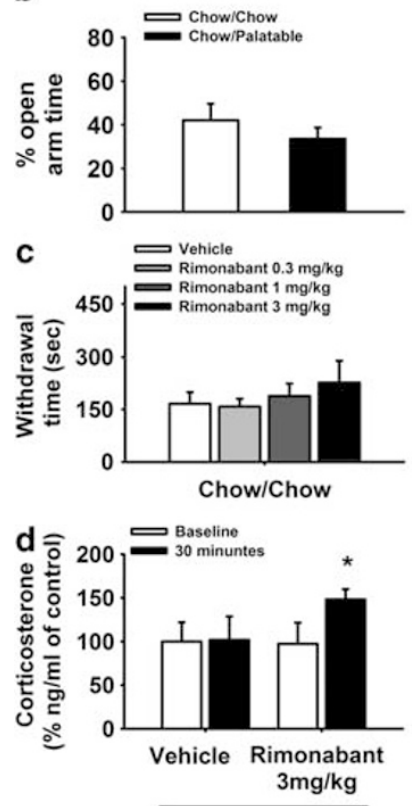

Chow/Chow

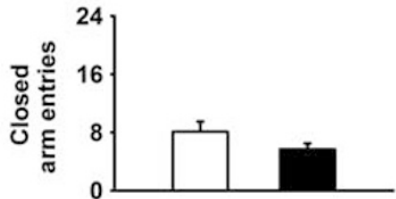

e $\quad$ Vehicle

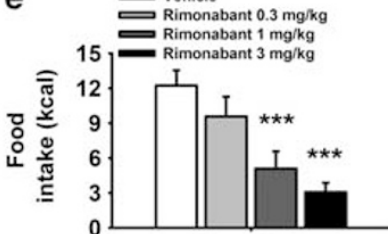

Chow/Chow

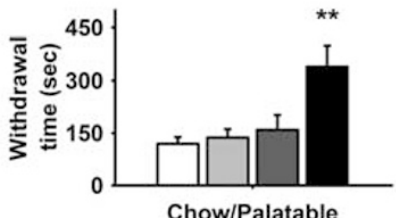

Chow/Palatable

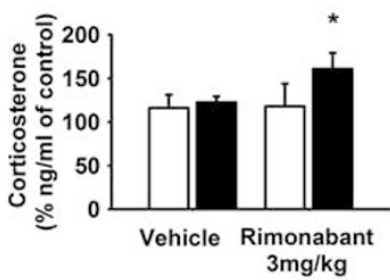

Chow/Palatable
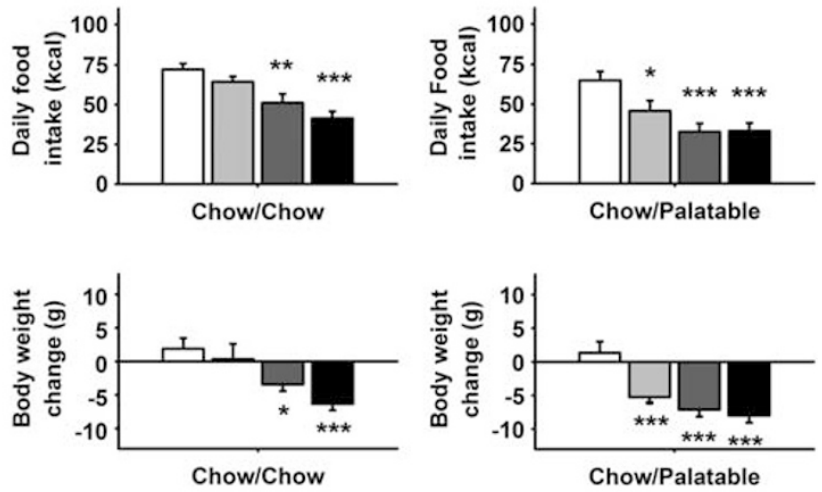


regular chow intake, and body weight change in female Wistar rats $(n=94)$ withdrawn for 4 days from chronic, intermittent access to a highly palatable diet.

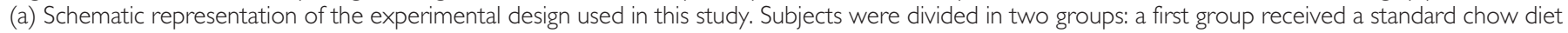

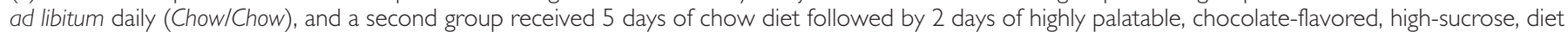



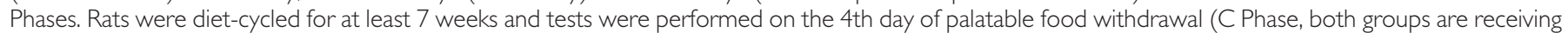

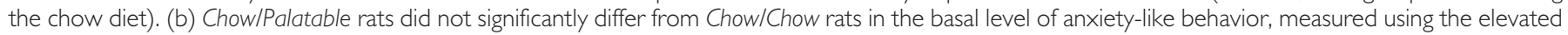

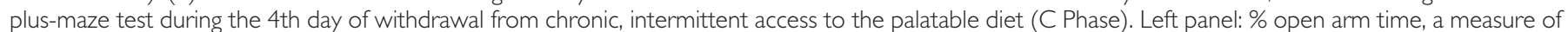

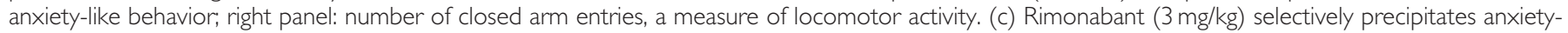

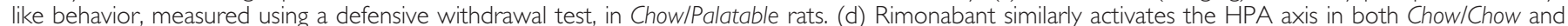

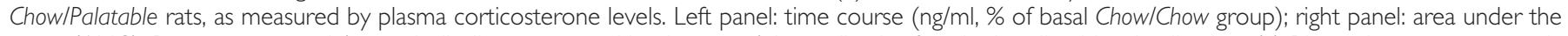
curve (AUC). Rats were treated (as symbolically represented by the arrow) immediately after the baseline blood collection. (e) Rimonabant more potently

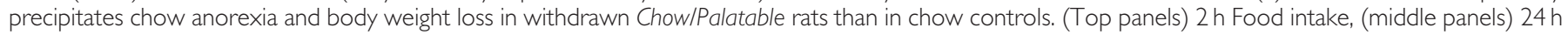
food intake, and (bottom panels) body weight change. Panels represent $M \pm$ SEM. Symbols denote: *significant difference from vehicle-treated group $p<0.05$, *** $p<0.01$, ***** $p<0.001$. 
Laboratory Animal Care (http://www.nap.edu/readingroom/ books/labrats), and were approved by the Institutional Animal Care and Use Committees of Boston University or Scripps Research Institute. No experimental procedures involved food or water restriction/deprivation.

\section{Drug}

Rimonabant (SR141716A, 5-(4-Chlorophenyl)-1-(2,4-dichloro-phenyl)-4-methyl-N-(piperidin-1-yl)-1 H-pyrazole-3carboxamide) $\mathrm{HCl}$ was solubilized in an 18:1:1 mixture of saline/ethanol/cremophor and was administered either intraperitoneally $(0,0.3,1,3 \mathrm{mg} / \mathrm{kg}, 1 \mathrm{ml} / \mathrm{kg}, 30 \mathrm{~min}$ pretreatment) or bilaterally into the central nucleus of the amygdala (CeA; $0,0.5,1.5 \mu \mathrm{g} /$ side, $30 \mathrm{~min}$ pretreatment). Intraperitoneal and site-specific doses of rimonabant were chosen based on previous literature (Caille and Parsons, 2006; Dore et al, 2013b; Gessa et al, 2006; Roche et al, 2007).

\section{Ad libitum Diet Alternation}

Ad libitum diet alternation was performed as previously described (Cottone et al, 2009a; Cottone et al, 2008, 2009b; Iemolo et al, 2012; see scheme in Figure 1a). After acclimation, rats were divided into two groups matched for food intake, body weight and feed efficiency from the previous 4 days. One group was provided a chow diet ('Chow') ad libitum 7 days a week (Chow/Chow), and a second group was provided chow ad libitum 5 days a week followed by 2 days of ad libitum access to a highly palatable, chocolate flavored, high-sucrose diet ('Palatable'; Chow/Palatable). Chow diet was the above-described Harlan Teklad LM-485 Diet 7012. The palatable diet was a nutritionally complete, high-sucrose $(50 \% \mathrm{kcal})$, AIN-76A-based diet that is comparable in macronutrient proportions and energy density to the chow diet (5TUL: $66.7 \%$ (kcal) carbohydrate, $12.7 \%$ fat, $20.6 \%$ protein, $344 \mathrm{cal} / 100 \mathrm{~g}$; TestDiet). For brevity, the first 5 days (chow only) and last 2 days (chow or palatable according to experimental group) of each week are referred to in all experiments as $\mathrm{C}$ and $\mathrm{P}$ phases (see scheme Figure 1a). Palatable diet was provided in GPF20 'J'-feeders (Ancare, Bellmore, NY). Diets were never concurrently available. All rats were diet cycled for at least 7 weeks (ranging from 8 to 11) and the number of weeks was equally represented in all the experimental groups. The length of diet cycles ( 7 days) reduces the likelihood that the estrous cycle (4-5 days) accounts for observed effects and resembles designs used in previous diet-cycling studies of female rats (Cottone et al, 2009b; Hagan and Moss, 1997).

\section{Intracranial Surgeries and Microinfusion Procedure}

Surgeries were performed following a previously described procedure (Sabino et al, 2007). The cannula coordinates used were $\mathrm{A} / \mathrm{P}-0.2 \mathrm{~mm}, \mathrm{M} / \mathrm{L} \pm 4.1 \mathrm{~mm}, \mathrm{D} / \mathrm{V}-6.5 \mathrm{~mm}$. The interaural bar was set at +5 according to the atlas of Pellegrino (Pellegrino, 1979).

Drug was microinfused in the brain of rats as described previously (Blasio et al, 2013; Dore et al, 2013b). Microinfusions were performed in $0.5 \mu \mathrm{l}$ volume delivered over $2 \mathrm{~min}$. Cannula placement was verified at the conclusion of all testing.

\section{Behavioral Tests}

Food intake and body weight measurements. Food intake was measured at $2 \mathrm{~h}$ and $24 \mathrm{~h}$ later and rats' body weights at $24 \mathrm{~h}$. Rimonabant was administered intraperitoneally $(0,0.3,1,3 \mathrm{mg} / \mathrm{kg})$ or was microinfused within the $\mathrm{CeA}(0,0.5$ and $1.5 \mu \mathrm{g} / \mathrm{side})$. Treatments were administered during the first switch to palatable diet (first week, P Phase, 6th day of the cycle), or after 7 weeks of cycling on the 4 th day of withdrawal from palatable diet (C phase, 4 th day of the cycle), or after 7 weeks of cycling on the first day of renewed access to palatable diet (P Phase, 6th day of the cycle).

Defensive withdrawal test. The defensive withdrawal test was performed as previously described (Cottone et al, 2009b). Rats were diet-cycled for at least 7 weeks and tested during the 4th day of withdrawal from palatable diet (C Phase). Rats were pretreated with either vehicle or rimonabant $(0.3,1$, and $3 \mathrm{mg} / \mathrm{kg}$, i.p.).

Elevated Plus-maze test. The elevated plus-maze was performed as previously described (Cottone et al, 2009b; Dore et al, 2013a). Rats were diet-cycled for at least 7 weeks and tested on the 4th day of withdrawal from palatable diet (C Phase) for spontaneous anxiety-like behavior or following microinfusion of rimonabant into the CeA $(0.5 \mu \mathrm{g} / \mathrm{side})$.

\section{Tissue eCB Measurement}

Chow/Palatable $(n=23)$ rats were diet-cycled for at least 7 weeks. On the 4th day (C Phase) or on the 7th day (P Phase) the rats were killed right after the dark cycle onset and $\mathrm{CeA}$, nucleus accumbens (NAc), and lateral hypothalamus (LH) punches were stored at $-80^{\circ} \mathrm{C}$. The brain samples were not pooled together. Each data point represented the eCB level of an individual subject. Anandamide (AEA) and 2 -arachidonoylglycerol (2-AG) levels were quantified as previously described (Grimaldi et al, 2009).

\section{Quantitative Real-Time PCR}

To quantify $\mathrm{CB}_{1}$ mRNA levels, rats $(n=6)$ were diet-cycled for 7 weeks and then decapitated on the 4th day of the chow phase right after the dark cycle onset. Brains were quickly removed and sliced coronally in a brain matrix. CeA punches were stored at $-80^{\circ} \mathrm{C}$. Total RNA was extracted according to manufacturer recommendations (Invitrogen), reverse transcribed in cDNA and analyzed as previously described (Grimaldi et al, 2009).

\section{Western Blotting}

A different cohort of rats $(n=8)$ was diet-cycled for at least 7 weeks. On the 4th day of chow phase, rats were sacrificed and CeA punches were collected. Punches were homogenized in lysis buffer (20 mM HEPES, $\mathrm{pH}=7.4$, EDTA $2 \mathrm{mM}, 1 \% \mathrm{SDS}$, $10 \%$ sucrose) by sonication, and centrifuged at $10000 \times g$ for $20 \mathrm{~min}$ at $4{ }^{\circ} \mathrm{C}$. The supernatant was transferred to a new tube, and protein concentration in lysates was determined by the BCA assay (Pierce) using BSA as standard. Subsequently, the samples ( $70-80 \mu \mathrm{g}$ of total protein) were 
boiled for $5 \mathrm{~min}$ in Laemmli SDS loading buffer, loaded on 8-10\% SDS-polyacrylamide gel electrophoresis, and then transferred to a PVDF membrane. Filters were incubated overnight at $4{ }^{\circ} \mathrm{C}$ with monoclonal anti- $\mathrm{CB}_{1} \quad(209550$ N221/17, dilution 1:1000 Calbiochem, Millipore Billerica, MA, USA). The monoclonal anti-tubulin clone B-5-1-2 (dilution, 1:5000; Sigma-Aldrich) was used to check for equal protein loading. Reactive bands were detected by chemiluminescence (ECL or ECL-plus; Perkin-Elmer) and the images were analyzed on a Chemi-Doc station with Quantity-one software (Bio-Rad, Segrate MI, Italy).

\section{Plasma Corticosterone RIA}

Tail blood samples were collected after the 7th week of cycling from rats $(n=24)$ at four time points on the 4th day of the chow phase right after the dark cycle onset: basal condition and $30 \mathrm{~min}$ following rimonabant administration $(0,3 \mathrm{mg} / \mathrm{kg}$, i.p., $30 \mathrm{~min}$ pretreatment). Rimonabant was administered immediately after the basal blood collection. Plasma levels of corticosterone-like immunoreactivity levels were quantified as previously described (Cottone et al, 2009a).

\section{Statistical Analysis}

Student's $t$-tests were used to analyze factors with two levels. ANOVAs were performed to analyze factors with more than two levels. Following significant omnibus effect of ANOVAs $(p<0.05)$, Student-Newman-Keuls post-hoc comparison tests were used. The statistical packages used were Instat 3.0 (GraphPad, San Diego, CA), Systat 11.0 (SPSS, Chicago, IL) and Statistica 7 (StatSoft, Tulsa, OK).

\section{RESULTS}

\section{Rimonabant, Systemically Administered, Precipitates Anxiety-like Behavior in Rats Withdrawn from Palatable Diet Cycling}

To test the hypothesis that rimonabant treatment precipitates anxiety-like behavior during withdrawal from chronic intermittent access to palatable food, female Wistar rats were provided a chow diet ad libitum every day of the week (Chow/Chow) or were provided a chow diet for 5 days (C Phase) followed by a highly palatable, sugary diet for 2 days (P phase; Chow/Palatable; see scheme in Figure 1a; Cottone et al, 2009a; Cottone et al, 2009b). After at least 7 weeks of diet cycling, rats were administered rimonabant $(0,0.3,1,3 \mathrm{mg} / \mathrm{kg}$, i.p. $)$ and tested for anxiety-like behavior in the defensive withdrawal test and in the elevated plusmaze test following 4 days of withdrawal from the palatable diet. At this early protracted withdrawal time point, diet-cycled rats no longer show increased spontaneous (ie, non-precipitated) anxiety like-behavior in the elevated plus-maze $(t s(17)<1.46$, n.s. Figure $1 \mathrm{~b})$ or defensive withdrawal test (vehicle condition, Figure 1c). As shown in Figure 1c, two-way ANOVA revealed a main effect of treatment $(\mathrm{F}(1,59)=5.14, p<0.003)$; the highest dose of rimonabant $(3 \mathrm{mg} / \mathrm{kg})$ increased the time spent in the closed compartment, an anxiogenic-like effect, selectively in Chow/Palatable rats. To further confirm the precipitation of anxiety-like behavior in Chow/Palatable rats, a different cohort of rats was tested in the elevated plus-maze test using the dose which had effectively induced anxiety-like behavior in the defensive withdrawal test. A two-way ANOVA showed a main effect of treatment $(\mathrm{F}(1,37)=$ 13.47, $p<0.001$, Supplementary Figure 1A). Post hoc analysis revealed a significant decrease in percentage of time spent in the open arms in the rimonabant-treated Chow/Palatable group as compared with vehicle condition. No significant effect was observed in Chow/Chow control rats. No effect in the closed arm entries was observed $(\mathrm{F}(1,37)=1.92$, n.s.; Supplementary Figure 1B). Thus, rimonabant, systemically administered, precipitated anxiety-like behavior in rats withdrawn from chronic, intermittent access to palatable food.

\section{Effects of Systemic Administration of Rimonabant on the Adrenocortical Activation in Rats withdrawn from Palatable Diet Cycling}

Because rimonabant can activate the hypothalamic-pituitaryadrenal (HPA) axis (Patel and Hillard, 2008), we tested the hypothesis that rimonabant-induced anxiety-like behavior in diet-cycled rats was related to differential activation of the HPA axis in Chow/Palatable vs Chow/Chow rats. Three-way ANOVA analysis showed a main effect of drug treatment $(\mathrm{F}(1,20)=4.32, p \leqslant 0.05$; Figure $1 \mathrm{~d})$ and rimonabant increased corticosterone levels equally in both Chow/Palatable and Chow/Chow rats (Figure 1d). Thus, rimonabant-precipitated anxiety-like behavior in rats withdrawn from chronic, intermittent access to palatable food was independent from the degree of adrenocortical activation.

\section{Rimonabant Precipitates Anorexia and Body Weight Loss in rats Withdrawn from Palatable Diet Cycling}

Withdrawal from many drugs of abuse can induce anorexia and body weight loss (Aceto et al, 2001; Koga and Inukai, 1981; Tsuda et al, 1998; Supplementary ref 22-28). To determine whether rimonabant induced anorexia and body weight loss more potently in rats withdrawn from palatable food, we administered the $\mathrm{CB}_{1}$ receptor antagonist during the 4th day of abstinence (when precipitated anxiety likebehavior was observed). Two-way ANOVA revealed that rimonabant dose-dependently reduced food intake and body weight $(2 \mathrm{~h}: F(3,62)=14.62, p<0.001 ; 24 \mathrm{~h}: F(3,62)=$ $16.42, p<0.001$; body weight change: $F(3,62)=18.00$, $p<0.001$; Figure 1e and Supplementary Figure 2) with a minimum effective dose in Chow/Chow rats of $1 \mathrm{mg} / \mathrm{kg}$. However, the lowest dose of the $\mathrm{CB}_{1}$ receptor antagonist $(0.3 \mathrm{mg} / \mathrm{kg})$, known to be ineffective at reducing food intake and body weight in literature (Freedland et al, 2000) and the present study of Chow/Chow rats, significantly reduced 2-h chow intake by $\sim 50 \%$ in Chow/Palatable rats. Cumulative anorexia persisted through $24 \mathrm{~h}$, by which time the lowest rimonabant dose $(0.3 \mathrm{mg} / \mathrm{kg})$ had induced weight loss comparable in magnitude to the body weight lost following treatment with the highest dose $(3 \mathrm{mg} / \mathrm{kg})$. Thus, systemic rimonabant treatment dramatically reduced food intake and body weight in diet-cycled rats withdrawn from palatable food at a dose which does not reduce food intake in control conditions. 
Effects of Systemic Administration of Rimonabant on Compulsive Eating of Palatable Food

Next, we sought to determine the effects of systemic administration of rimonabant on the compulsive eating of highly palatable food. For this purpose, a different cohort of rats was diet cycled for at least 7 weeks, and rimonabant was administered $30 \mathrm{~min}$ before renewing access to the highly palatable diet $(\mathrm{C} \rightarrow \mathrm{P})$. Two-way ANOVA analysis showed that rimonabant dose-dependently reduced food intake and body weight, as expected $(2 \mathrm{~h}: F(3,36)=5.30, p<0.003$; $24 \mathrm{~h}: F(3,36)=8.91, p<0.001$; weight change: $F(3,36)=8.43$, $p<0.001$; Figure 2a and Supplementary Figures $3 \mathrm{~A}$ and 4A). However, although Chow/Chow rats appropriately responded to the effects of rimonabant, drug treatment did not significantly affect food intake upon renewed access to the palatable diet in Chow/Palatable rats. Thus, contrary to what observed during withdrawal from palatable food, rimonabant showed decreased anorectic potency to reduce palatable diet intake in rats with a history of chronic, intermittent access to palatable food.

\section{Effects of Systemic Administration of Rimonabant on Intake of Palatable Food During the First Access}

To evaluate whether the lack of sensitivity to the anorectic effects of rimonabant in diet-cycled rats refeeding on palatable diet was determined by the diet cycling (as opposed to the diet itself), a different cohort of rats was challenged with the $3 \mathrm{mg} / \mathrm{kg}$ of rimonabant $30 \mathrm{~min}$ before their very first access to the palatable food, with chow-fed rats tested concurrently. As shown by one-way ANOVA analysis, rimonabant maintained its acute anorectic activity in rats that underwent a single switch to the highly palatable diet $(\mathrm{F}(1,30)=28.45, p<0.001$; Figure $2 \mathrm{~b}$ and Supplementary Figures $3 \mathrm{~B}$ and $4 \mathrm{~B}$ ).Thus, the decreased anorectic potency of rimonabant in reducing palatable diet intake in rats with a history of chronic, intermittent access to


Figure 2 Effects of rimonabant (30 min pretreatment, $0,0.3,1,3 \mathrm{mg} / \mathrm{kg}$, i.p.) on food intake in female Wistar rats $(n=48)$ during day 6th (P phase, when Chow/Chow rats are fed chow diet and Chow/Palatable rats are fed the highly palatable diet). (a) Rimonabant fails to reduce 2-h intake of the highly palatable diet. (b) Rimonabant reduces 2-h food intake during the first access to the palatable diet in Chow/Palatable rats. Panels represent $M \pm$ SEM. Symbols denote: *significant difference from vehicle condition $p<0.05$, ***** $p<0.001$. palatable food, was determined by diet cycling and not by the diet itself.

\section{eCBs Levels in the CeA of Rats Withdrawn from Palatable Diet Cycling}

The increased sensitivity to the anxiogenic-like and anorectic effects of rimonabant in Chow/Palatable rats withdrawn from palatable food was suggestive of heightened $\mathrm{CB}_{1}$ receptor signaling. To investigate whether increased $\mathrm{eCB}$ tone occurred during palatable food withdrawal, we measured tissue levels of AEA and 2-AG in the CeA, the $\mathrm{NAc}$, and the LH of a separate group of rats that underwent the same diet schedules described above (Figure 1a). As shown in Figure 3a, withdrawal from the palatable diet increased the levels of 2-AG in the CeA of Chow/Palatable rats as compared with Chow/Chow rats. Levels of 2-AG returned to control-like levels upon renewed access to palatable food $(\mathrm{F}(2,21)=5.028, p<0.02)$. No significant group differences were observed in AEA levels within the $\mathrm{CeA}$, suggesting specificity of the 2-AG effect. In addition, neither 2-AG nor AEA levels of Chow/Palatable rats differed in the other brain areas analyzed when compared with Chow/Chow rats (2-AG: NAc, $F(2,20)=0.58$, n.s.; LH, $F(2,20)=0.43$, n.s.; AEA: NAc, $F(2,20)=1.89$, n.s.; CeA, $F(2,20)=0.45$, n.s.; LH $F(2,20)=0.58$, n.s.; Supplementary Figure 5). Thus, withdrawal from intermittent access to highly palatable food increased 2-AG levels in the CeA.

\section{$\mathrm{CB}_{1}$ mRNA and Protein Expression in the CeA of Rats Withdrawn from Palatable Diet Cycling}

Given the increased 2-AG content seen in the CeA during withdrawal from palatable food, we investigated the gene expression of $\mathrm{CB}_{1}$ receptor in the same area using quantitative real-time PCR in a different cohort of rats. As shown in Figure 3b, Chow/Palatable rats withdrawn from palatable food exhibited three-fold higher levels of $\mathrm{CB}_{1}$ mRNA expression in the CeA as compared with Chow/Chow rats $(t(4)=3.55, p<0.02$; Figure $3 b)$. To confirm the results obtained with the mRNA expression, the $\mathrm{CB}_{1}$ protein levels in the CeA were also measured using western blotting. Figure $3 \mathrm{c}$ shows a significant increase in the $\mathrm{CB}_{1}$ receptor in Chow/Palatable rats withdrawn from palatable food $(t(6)=2.77, p<0.03)$. Thus, withdrawal from intermittent access to highly palatable food, increased both the $\mathrm{CB}_{1}$ receptor gene and protein expression in the CeA.

\section{Microinfusion of Rimonabant in the CeA Precipitates Anxiety-like Behavior in Rats Withdrawn from Palatable Diet Cycling}

Next, we tested the hypothesis that rimonabant could site-specifically precipitate anxiogenic-like behavior when locally microinfused to interrupt the increased $\mathrm{CeA} \mathrm{CB}_{1}$ signaling of rats withdrawn from palatable food. We bilaterally implanted diet-cycled rats with cannula targeting the CeA and then tested rats in the elevated plus-maze following microinfusion of rimonabant $(0.5 \mu \mathrm{g} / \mu \mathrm{l})$ during the 4th day of withdrawal. As shown in Figure 4a, intra-CeA rimonabant microinfusion reduced the percentage of time spent in the open arms, an anxiogenic-like effect, selectively 

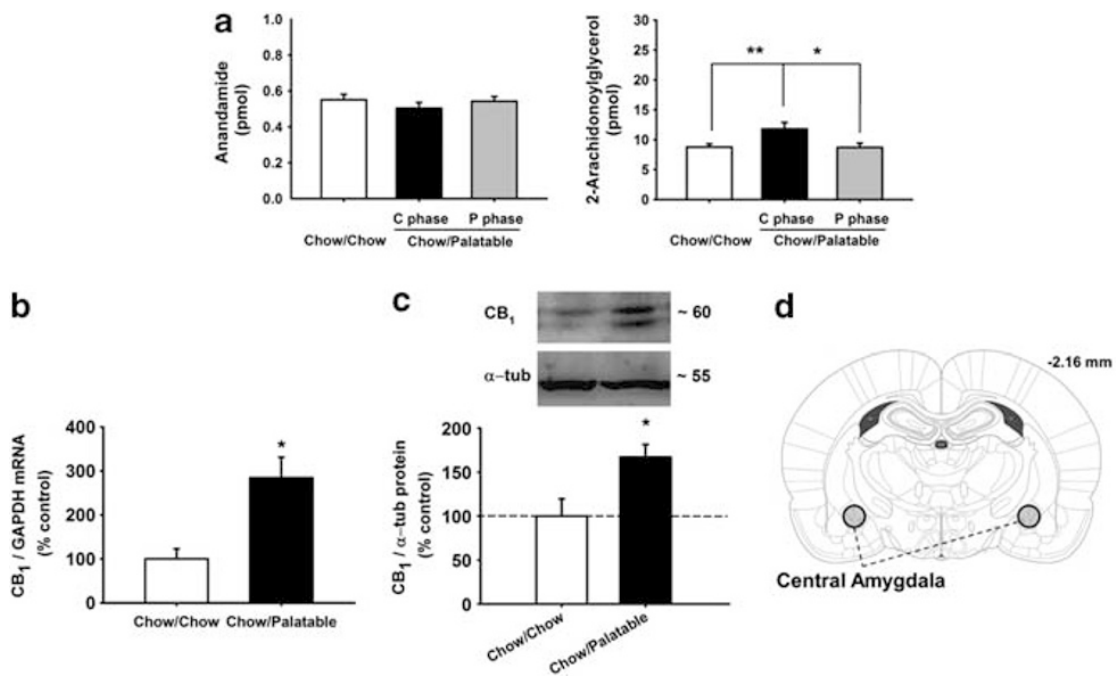

Figure 3 Effects of palatable diet alternation on (a) (left panel) anandamide (AEA) and (right panel) 2-arachidonoylglycerol (2-AG) levels ( $n=16$ ), (b) $C B$, receptor gene expression $(n=6)$ and (c) protein expression $(n=8)$ in the CeA. (d) Drawing of rat brain coronal slices used for mass spectrometry and quantitative RT-PCR. Circles show brain regions that were punched out. Rats were diet-cycled for 7 weeks, and CeA punches were collected during the 4th day of palatable food withdrawal (C Phase). 2-AG levels in the CeA of Chow/Palatable rats increased when palatable diet was withdrawn (day 4) and returned to chow-fed control levels upon renewing the access to the palatable diet (day 7). Values are expressed as \% of Chow/Chow group (see Supplementary Figure 4 for absolute levels). Panels represent $M \pm$ SEM. Symbols denote: *significant difference from Chow/Chow group $p<0.05$, *** $<0.0$ I.

in Chow/Palatable rats $(\mathrm{F}(1,36)=5.27, p<0.02)$. No significant group difference was detected in the number of closed arm entries, an index of locomotor activity $(\mathrm{F}(1,36)=0.26$, n.s. $)$. Confirming the specificity of the effects for $\mathrm{CB}_{1}$ receptors in the CeA, no effect was observed in the elevated plus-maze of subjects with misplaced cannulae $(\mathrm{F}(1,17)=0.02$, n.s. and $\mathrm{F}(1,17)=1.87$, n.s., $\%$ open arm time and closed arm entries, respectively. Therefore, site-specific antagonism of $\mathrm{CB}_{1}$ receptors in the $\mathrm{CeA}$ is sufficient to precipitate anxiety-like behavior in rats withdrawn from chronic, intermittent access to a highly palatable diet. The results support the hypothesis that the anxiogenic-like state elicited by systemic rimonabant in diet-cycled animals withdrawn from palatable food is mediated by the CeA.

\section{Microinfusion of Rimonabant in the CeA Precipitates Anorexia in Rats Withdrawn from Palatable Diet Cycling}

We then tested the hypothesis that intra-CeA administration of rimonabant was sufficient to reproduce the precipitated anorectic effect of systemic rimonabant in withdrawn Chow/Palatable rats. Two-way ANOVA revealed a diet $\times$ treatment interaction $(\mathrm{F}(4,52)=4.39 \quad p<0.003$; Figure $4 \mathrm{~b})$. As hypothesized, the highest dose of rimonabant locally injected into the CeA $(1.5 \mu \mathrm{g} / \mathrm{side})$ selectively decreased chow intake in Chow/Palatable rats during withdrawal from palatable food, without altering the intake of Chow/Chow rats (Figure 4b). Furthermore, site-specific microinfusion of rimonabant within the CeA did not affect food intake in palatable diet-fed Chow/Palatable rats. Once again, analysis of subjects with misplaced cannulae showed no rimonabant effect on food intake $(\mathrm{F}(2,42)=0.94$, n.s. $)$, confirming the specificity of the effects for the CeA. The findings support the hypothesis that $\mathrm{CeA} \mathrm{CB}_{1}$ receptors mediate the precipitated anorectic effects of rimonabant in rats withdrawn from chronic, intermittent access to a highly palatable diet.

\section{DISCUSSION}

The present study provides functional evidence that rimonabant precipitates a negative emotional state in rats withdrawn from chronic, intermittent access to a highly palatable diet and that blockade of $\mathrm{CB}_{1}$ receptor signaling in the CeA mediates these effects. Specifically, we demonstrate that systemic administration of rimonabant precipitates anxiety-like behavior and more potently induces anorexia and weight loss in rats during early protracted withdrawal from a palatable high-sucrose diet compared with chow-fed controls. In addition, at a time when diet-cycled rats no longer showed the increased spontaneous anxiety-like behavior elicited by acute withdrawal from this diet (Cottone et al, 2009a; Cottone et al, 2009b), they still exhibited increased vulnerability to the anxiogenic-like effects of rimonabant (Haller et al, 2004). These results are consistent with the hypothesis that rats withdrawn from chronic, palatable diet cycling become vulnerable to the pharmacological effects of rimonabant. Indeed, spontaneous or precipitated withdrawal from many drugs of abuse can induce not only anorexia and body weight loss (Aceto et al, 2001; Koga and Inukai, 1981; Tsuda et al, 1998) (Supplementary ref 22-28), but also anxiety-like behavior (Basso et al, 1999; George et al, 2007; Rodriguez de Fonseca et al, 1997; Schulteis et al, 1998). Also noteworthy, is the apparent discrepancy between the systemic lowest effective doses in the food intake and anxiety-like behavior experiments, which is very likely determined by the additional contribution of peripheral mechanisms to the anorectic effects of rimonabant (Di Marzo and Matias, 2005).

Interestingly, rimonabant treatment did not affect anxiety-like behavior in control rats, confirming the suggested role for $\mathrm{CB}_{1}$ receptors in modulating anxiety only in conditions of heightened stress (either external or internal; 
a
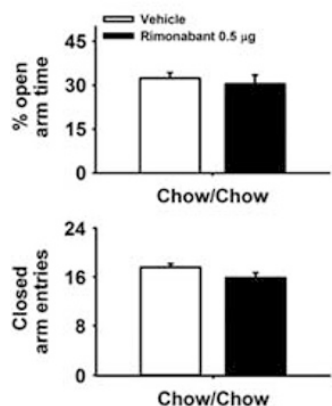

Chow/Chow
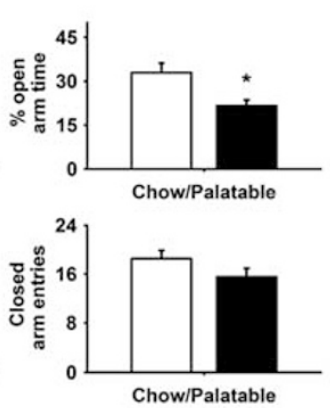

C

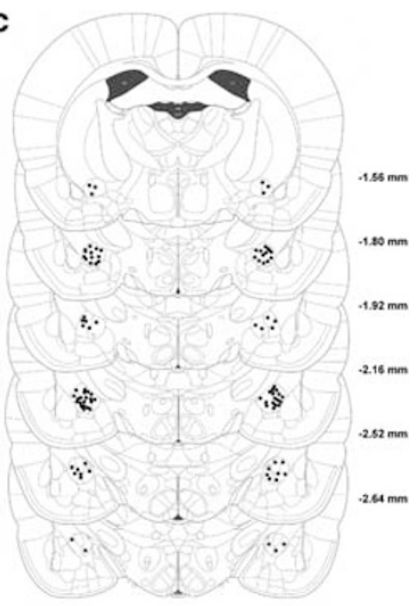

b


Figure 4 Effects of intra-CeA injection of rimonabant ( 30 min pretreatment, 0, 0.5, $1.5 \mu \mathrm{g} / \mathrm{side}$ ) on anxiety-like behavior and food intake in diet-cycled female Wistar rats $(n=46)$. (a) Rimonabant, microinfused within the CeA during the 4th day of withdrawal from palatable food (C Phase), selectively precipitates anxiety-like behavior, measured using an elevated plus-maze test, in Chow/Palatable rats. (Top panels) \% open arm time, a measure of anxietylike behavior; (bottom panels) number of closed arm entries, a measure of locomotor activity. (b) Rimonabant, microinfused into the CeA during the 4th day of withdrawal from palatable food (C Phase), selectively precipitates chow anorexia; in contrast, microinfusion during the 6th day (P Phase), does not affect intake of the highly palatable diet in Chow/Palatable rats. (c) Drawing of coronal rats' brain slices. Dots represent the injection sites in the CeA included in the data analysis. Panels represent $M \pm$ SEM. Symbols denote: *significant difference from vehicle condition $p<0.05$, *** $p<0.01$.

Haller et al, 2004). In addition, rimonabant-precipitated anxiety-like behavior in rats withdrawn from chronic, intermittent access to palatable food was independent of the degree of adrenocortical activation. This finding confirms the previous observation that the negative emotional state in rats withdrawn from chronic, intermittent access to a highly palatable diet is independent of HPA axis activation (Cottone et al, 2009a).

The increased sensitivity to the anxiogenic-like and anorectic effects of rimonabant in diet-cycled rats withdrawn from palatable food was accompanied by molecular evidence of increased 2-AG-CB ${ }_{1}$ signaling in the $\mathrm{CeA}$, a brain area involved in emotional processing and in the emergence of negative affect during abstinence from substances of abuse (Cottone et al, 2009a; Koob and Volkow, 2010). Consistent with a key functional role for the $\mathrm{CeA}$ in mediating the rimonabant-induced negative emotional state, microinfusion of rimonabant into the CeA was sufficient to precipitate both anxiety-like behavior and chow anorexia selectively in diet-cycled rats withdrawn from the palatable diet and not in chow controls.

Interestingly, in this study, rimonabant failed to reduce compulsive eating upon renewed access to the highly palatable diet. The reduced effectiveness of $\mathrm{CB}_{1}$ receptor blockade on excessive palatable food intake is consistent with what we previously published (Parylak et al, 2012). Compulsive eating observed here is analogous to the behavior observed in other animal models of drug dependence, which is characterized by the relief of anxiety by performing the compulsive behavior (Cottone et al, 2009b; Iemolo et al, 2013; Koob, 2009; Koob and Volkow, 2010). However, it is important to mention that in preclinical research compulsive behavior is also defined as a behavior, which occurs in spite of negative consequences (Belin et al, 2008; Davis et al, 2010; Dore et al, 2013b; Johnson and Kenny, 2010).

Collectively, the biochemical and pharmacological data suggest that the 2-AG-CB 1 signaling in the $\mathrm{CeA}$ is increased during abstinence from palatable food, perhaps as a compensatory mechanism to oppose the negative emotional state produced by withdrawal. Acute (5-9h) withdrawal from chronic, intermittent access to the highly palatable diet used in the present study is known to produce a stresslike withdrawal state, which is characterized by anxiety-like behavior, hypophagia of the otherwise acceptable chow diet, and body weight loss (Cottone et al, 2009a; Cottone et al, 2008, 2009b; Iemolo et al, 2012). This palatable food withdrawal-dependent behavioral outcome is accompanied by the recruitment of the amygdaloid CRF-CRF 1 stress system in the CeA (Cottone et al, 2009a; Koob and Volkow, 2010). Therefore, consistent with the proposed anxiolytic role of eCBs (Patel and Hillard, 2008), the neuroadaptive elevation of $2-\mathrm{AG}^{-\mathrm{CB}_{1}}$ levels seen during early protracted withdrawal may serve to counteract the acute withdrawallike state. Accordingly, blockade of $\mathrm{CB}_{1}$ signaling with rimonabant would prevent the compensatory, anxiolyticlike effects of $2-\mathrm{AG}$ and, thereby, unmask the underlying anxiogenic-like withdrawal syndrome.

The hypothesis proposed here resembles the conceptualization of naloxone precipitated opiate withdrawal-like 
symptoms during abstinence (Rothwell et al, 2012) and the view that amygdaloid 2-AG is recruited during chronic stressful events to promote habituation to stress (Patel and Hillard, 2008). Indeed, repeated but not single homotypic restraint stress has been demonstrated to increase the amygdaloid 2-AG, consistent with a mechanism which opposes the behavioral and neuronal responses to aversive stimuli and contributes to the expression of habituation (Patel et al, 2005). Moreover, the present results are consistent with the ability of rimonabant to precipitate negative emotional behavior during chronic exposure to cannabinoids and opiates (Navarro et al, 2001; Rodriguez de Fonseca et al, 1997; Valverde et al, 2000). Indeed, rimonabant precipitated an opiate-like withdrawal syndrome as shown by increased somatic signs of withdrawal and increased place aversion in morphine-dependent rats, without inducing any intrinsic effect in non-dependent subjects (Navarro et al, 2001). In addition, rimonabant treatment precipitated somatic signs of withdrawal in mice made dependent on chronic administration of $\Delta 9$-tetrahydrocannabinol (Valverde et al, 2000).

It is notable that, the role of $\mathrm{CB}_{1}$ antagonism in regulating anxiety-like behavior in relation to other neurotransmitters has been shown to vary as a function of the system studied. For example, although antagonism of $\mathrm{CB}_{1}$ receptor precipitates withdrawal from opiates and cannabinoids (Navarro et al, 2001; Rodriguez de Fonseca et al, 1997; Valverde et al, 2000), it has also been shown, at low doses, to reduce anxiety-like responses induced by chronic cocaine and CRF injections (Kupferschmidt et al, 2012b). Furthermore, although $\mathrm{CB}_{1}$ receptor antagonism blocked forced swim-induced reinstatement of cocaine-seeking behavior (Vaughn et al, 2012), it did not affect reinstatement of cocaine seeking by footshock stress, an effect known to be mediated by CRF (De Vries et al, 2001; Kupferschmidt et al, 2012a).

Importantly, neither systemic nor intra-CeA administration of rimonabant potentiated anorexia when rats had ongoing access to the palatable diet. The lack of precipitated anorexia is consistent with the observation that elevations in $2-A G-B_{1}$ levels were seen selectively during protracted withdrawal from the palatable diet and not when rats had ongoing access, further supporting the proposed mechanism of action. Rather, systemic rimonabant less potently reduced palatable food intake in diet-cycled rats. However, when rimonabant was administered during the first access to the palatable food, drug treatment was indeed able to decrease food intake and body weight in rats without a history of diet cycling, suggesting that chronic, intermittent access to palatable food attenuates the anorectic potency of $\mathrm{CB}_{1}$ antagonist to reduce palatable food intake.

In conclusion, our findings suggest an addiction-like, neuroadaptive functional mechanism for the emergence of severe psychiatric side-effects following rimonabant treatment in obese patients. We propose that rimonabant may precipitate a withdrawal-like syndrome in a subpopulation of obese individuals 'withdrawing' from palatable food as they attempt to lose weight (eg, by dieting). Rimonabant may do so by preventing the anti-stress/anti-withdrawal effects of heightened 2-AG-CB $\mathrm{B}_{1}$ signaling in the CeA during early protracted withdrawal, leading to the emergence of negative emotional symptoms. The present findings support the hypothesis that recently developed, peripherally-restricted $\mathrm{CB}_{1}$ receptor antagonists/inverse agonists (Engeli, 2012) could be a suitable pharmacologic strategy to treat obesity, by avoiding the adverse CeA-mediated psychiatric side-effects of blood-brain barrier penetrating $\mathrm{CB}_{1}$ ligands like rimonabant.

\section{FUNDING AND DISCLOSURE}

This publication was made possible by grant numbers DA023680, DA030425, MH091945, MH093650, AA016731, AA06420, and DK070118 from the National Institute on Drug Abuse (NIDA), the National Institute of Mental Health (NIMH), the National Institute on Alcohol Abuse and Alcoholism (NIAAA), and the National Institute on Diabetes, Digestive and Kidney Disorders, by the Peter Paul Career Development Professorship (P.C.) and by Boston University's Undergraduate Research Opportunities Program (UROP). This research was also supported by the NIH Intramural Research Programs of the National Institute on Drug Abuse, and the National Institute of Alcohol Abuse and Alcoholism, NIH, DHHS. The authors declare no conflict of interest.

\section{ACKNOWLEDGEMENTS}

We thank Stephen St Cyr, Aditi R Narayan, Jina Kwak, and Jin Won Park for the technical assistance, as well as Rahul Ramesh Rao and Anika Begum for editorial assistance.

\section{REFERENCES}

Aceto MD, Scates SM, Martin BB (2001). Spontaneous and precipitated withdrawal with a synthetic cannabinoid, WIN 55212-2. Eur J Pharmacol 416: 75-81.

Avena NM, Rada P, Hoebel BG (2008). Evidence for sugar addiction: behavioral and neurochemical effects of intermittent, excessive sugar intake. Neurosci Biobehav Rev 32: 20-39.

Basso AM, Spina M, Rivier J, Vale W, Koob GF (1999). Corticotropin-releasing factor antagonist attenuates the "anxiogenic-like" effect in the defensive burying paradigm but not in the elevated plus-maze following chronic cocaine in rats. Psychopharmacology (Berl) 145: 21-30.

Belin D, Mar AC, Dalley JW, Robbins TW, Everitt BJ (2008). High impulsivity predicts the switch to compulsive cocaine-taking. Science 320: 1352-1355.

Blasio A, Steardo L, Sabino V, Cottone P (2013). Opioid system in the medial prefrontal cortex mediates binge-like eating. Addict Biol (doi:10.1111/adb.12033).

Caille S, Parsons LH (2006). Cannabinoid modulation of opiate reinforcement through the ventral striatopallidal pathway. Neuropsychopharmacology 31: 804-813.

Corwin RL, Grigson PS (2009). Symposium overview-Food addiction: fact or fiction? J Nutr 139: 617-619.

Cottone P, Sabino V, Roberto M, Bajo M, Pockros L, Frihauf JB et al (2009a). CRF system recruitment mediates dark side of compulsive eating. Proc Natl Acad Sci USA 106: 20016-20020.

Cottone P, Sabino V, Steardo L, Zorrilla EP (2008). Intermittent access to preferred food reduces the reinforcing efficacy of chow in rats. Am J Physiol Regul Integr Comp Physiol 295: R1066-R1076.

Cottone P, Sabino V, Steardo L, Zorrilla EP (2009b). Consummatory, anxiety-related and metabolic adaptations in female rats 
with alternating access to preferred food. Psychoneuroendocrinology 34(1): 38-49.

Davis JF, Loos M, Di Sebastiano AR, Brown JL, Lehman MN, Coolen LM (2010). Lesions of the medial prefrontal cortex cause maladaptive sexual behavior in male rats. Biol Psychiatry 67: 1199-1204.

De Vries TJ, Shaham Y, Homberg JR, Crombag H, Schuurman K, Dieben J et al (2001). A cannabinoid mechanism in relapse to cocaine seeking. Nat Med 7: 1151-1154.

Di Marzo V, Matias I (2005). Endocannabinoid control of food intake and energy balance. Nat Neurosci 8: 585-589.

Di Marzo V, Piscitelli F, Mechoulam R (2011). Cannabinoids and endocannabinoids in metabolic disorders with focus on diabetes. Handb Exp Pharmacol 203: 75-104.

Dore R, Iemolo A, Smith KL, Wang X, Cottone P, Sabino V (2013a). CRF Mediates the Anxiogenic and Anti-Rewarding, But Not the Anorectic Effects of PACAP. Neuropsychopharmacology (doi:10.1038/npp.2013.113).

Dore R, Valenza M, Wang X, Rice KC, Sabino V, Cottone P (2013b). The inverse agonist of CB receptor SR141716 blocks compulsive eating of palatable food. Addict Biol (doi:10.1111/adb.12056).

Engeli S (2012). Central and peripheral cannabinoid receptors as therapeutic targets in the control of food intake and body weight. Handb Exp Pharmacol 209: 357-381.

Epstein DH, Shaham Y (2010). Cheesecake-eating rats and the question of food addiction. Nat Neurosci 13: 529-531.

Freedland CS, Poston JS, Porrino LJ (2000). Effects of SR141716A, a central cannabinoid receptor antagonist, on food-maintained responding. Pharmacol Biochem Behav 67: 265-270.

Gaetani S, Kaye WH, Cuomo V, Piomelli D (2008). Role of endocannabinoids and their analogues in obesity and eating disorders. Eat Weight Disord 13: e42-e48.

George O, Ghozland S, Azar MR, Cottone P, Zorrilla EP, Parsons $\mathrm{LH}$ et al (2007). CRF-CRF1 system activation mediates withdrawal-induced increases in nicotine self-administration in nicotine-dependent rats. Proc Natl Acad Sci USA 104: 17198-17203.

Gessa GL, Orru A, Lai P, Maccioni P, Lecca R, Lobina C et al (2006). Lack of tolerance to the suppressing effect of rimonabant on chocolate intake in rats. Psychopharmacology (Berl) 185: 248-254.

Goldberg SR, Schuster CR (1969). Nalorphine: increased sensitivity of monkeys formerly dependent on morphine. Science 166: 1548-1549.

Grimaldi P, Orlando P, Di Siena S, Lolicato F, Petrosino S, Bisogno $\mathrm{T}$ et al (2009). The endocannabinoid system and pivotal role of the CB2 receptor in mouse spermatogenesis. Proc Natl Acad Sci USA 106: 11131-11136.

Hagan MM, Moss DE (1997). Persistence of binge-eating patterns after a history of restriction with intermittent bouts of refeeding on palatable food in rats: implications for bulimia nervosa. Int $J$ Eat Disord 22: 411-420.

Haller J, Varga B, Ledent C, Barna I, Freund TF (2004). Contextdependent effects of $\mathrm{CB} 1$ cannabinoid gene disruption on anxietylike and social behaviour in mice. Eur J Neurosci 19: 1906-1912.

Iemolo A, Blasio A St, Cyr SA, Jiang F, Rice KC, Sabino V et al (2013). CRF-CRF receptor system in the central and basolateral nuclei of the amygdala differentially mediates excessive eating of palatable food. Neuropsychopharmacology (doi:10.1038/npp. 2013.147).

Iemolo A, Valenza M, Tozier L, Knapp CM, Kornetsky C, Steardo L et al (2012). Withdrawal from chronic, intermittent access to a highly palatable food induces depressive-like behavior in compulsive eating rats. Behav Pharmacol 23: 593-602.

Johnson PM, Kenny PJ (2010). Dopamine D2 receptors in addiction-like reward dysfunction and compulsive eating in obese rats. Nat Neurosci 13: 635-641.

Kirkham TC (2009). Cannabinoids and appetite: food craving and food pleasure. Int Rev Psychiatry 21: 163-171.
Koga Y, Inukai T (1981). Characterization of withdrawal syndrome of morphine-dependent rats prepared by intermittent infusion technique. Psychopharmacology (Berl) 73: 230-235.

Koob GF (2009). Neurobiological substrates for the dark side of compulsivity in addiction. Neuropharmacology 56(Suppl 1): 18-31.

Koob GF, Volkow ND (2010). Neurocircuitry of addiction. Neuropsychopharmacology 35: 217-238.

Kupferschmidt DA, Klas PG, Erb S (2012a). Cannabinoid CB1 receptors mediate the effects of corticotropin-releasing factor on the reinstatement of cocaine seeking and expression of cocaine-induced behavioural sensitization. Br J Pharmacol 167: 196-206.

Kupferschmidt DA, Newman AE, Boonstra R, Erb S (2012b). Antagonism of cannabinoid 1 receptors reverses the anxietylike behavior induced by central injections of corticotropinreleasing factor and cocaine withdrawal. Neuroscience 204: $125-133$.

Liu J, Schulteis G (2004). Brain reward deficits accompany naloxone-precipitated withdrawal from acute opioid dependence. Pharmacol Biochem Behav 79: 101-108.

Lukas SE, Griffiths RR (1982). Precipitated withdrawal by a benzodiazepine receptor antagonist (Ro 15-1788) after 7 days of diazepam. Science 217: 1161-1163.

Malin DH, Lake JR, Carter VA, Cunningham JS, Hebert KM, Conrad DL et al (1994). The nicotinic antagonist mecamylamine precipitates nicotine abstinence syndrome in the rat. Psychopharmacology (Berl) 115: 180-184.

Moreira FA, Grieb M, Lutz B (2009). Central side-effects of therapies based on CB1 cannabinoid receptor agonists and antagonists: focus on anxiety and depression. Best Pract Res Clin Endocrinol Metab 23: 133-144.

Navarro M, Carrera MR, Fratta W, Valverde O, Cossu G, Fattore L et al (2001). Functional interaction between opioid and cannabinoid receptors in drug self-administration. J Neurosci 21: 5344-5350.

Pacher P, Batkai S, Kunos G (2006). The endocannabinoid system as an emerging target of pharmacotherapy. Pharmacol Rev 58: 389-462.

Parylak SL, Cottone P, Sabino V, Rice KC, Zorrilla EP (2012). Effects of $\mathrm{CB} 1$ and $\mathrm{CRF} 1$ receptor antagonists on binge-like eating in rats with limited access to a sweet fat diet: lack of withdrawal-like responses. Physiol Behav 107: 231-242.

Parylak SL, Koob GF, Zorrilla EP (2011). The dark side of food addiction. Physiol Behav 104: 149-156.

Patel S, Hillard CJ (2008). Adaptations in endocannabinoid signaling in response to repeated homotypic stress: a novel mechanism for stress habituation. Eur J Neurosci 27: 2821-2829.

Patel S, Roelke CT, Rademacher DJ, Hillard CJ (2005). Inhibition of restraint stress-induced neural and behavioural activation by endogenous cannabinoid signalling. Eur J Neurosci 21: 1057-1069.

Paterson NE, Markou A (2004). Prolonged nicotine dependence associated with extended access to nicotine self-administration in rats. Psychopharmacology (Berl) 173: 64-72.

Pellegrino A (1979). A stereotaxic atlas of the rat brain. Plenum: New York.

Roche M, O'Connor E, Diskin C, Finn DP (2007). The effect of $\mathrm{CB}(1)$ receptor antagonism in the right basolateral amygdala on conditioned fear and associated analgesia in rats. Eur J Neurosci 26: 2643-2653.

Rodriguez de Fonseca F, Carrera MR, Navarro M, Koob GF, Weiss F (1997). Activation of corticotropin-releasing factor in the limbic system during cannabinoid withdrawal. Science 276: 2050-2054.

Rosenberg HC, Chiu TH (1982). An antagonist-induced benzodiazepine abstinence syndrome. Eur J Pharmacol 81: 153-157.

Rothwell PE, Thomas MJ, Gewirtz JC (2012). Protracted manifestations of acute dependence after a single morphine exposure. Psychopharmacology (Berl) 219: 991-998. 
Sabino V, Cottone P, Steardo L, Schmidhammer H, Zorrilla EP (2007). 14-Methoxymetopon, a highly potent mu opioid agonist, biphasically affects ethanol intake in Sardinian alcohol-preferring rats. Psychopharmacology (Berl) 192: 537-546.

Schulteis G, Yackey M, Risbrough V, Koob GF (1998). Anxiogeniclike effects of spontaneous and naloxone-precipitated opiate withdrawal in the elevated plus-maze. Pharmacol Biochem Behav 60: 727-731.

Sidhpura N, Parsons LH (2011). Endocannabinoid-mediated synaptic plasticity and addiction-related behavior. Neuropharmacology 61: 1070-1087.
Tsuda M, Suzuki T, Misawa M (1998). NMDA receptor antagonists potently suppress the spontaneous withdrawal signs induced by discontinuation of long-term diazepam treatment in Fischer 344 rats. Brain Res 790: 82-90.

Valverde O, Maldonado R, Valjent E, Zimmer AM, Zimmer A (2000). Cannabinoid withdrawal syndrome is reduced in preproenkephalin knock-out mice. J Neurosci 20: 9284-9289.

Vaughn LK, Mantsch JR, Vranjkovic O, Stroh G, Lacourt M, Kreutter $M$ et al (2012). Cannabinoid receptor involvement in stress-induced cocaine reinstatement: potential interaction with noradrenergic pathways. Neuroscience 204: 117-124.

Supplementary Information accompanies the paper on the Neuropsychopharmacology website (http://www.nature.com/npp) 